has had during this period is oral iron There has been no evidence of any leukopenia throughout this treatment.

In view of the subjective benefit achieved in this case intravesical palliative chemotherapy with cyclophosphamide in locally advanced carcinoma of the bladder may merit further study. Thiotepa and other cytotoxic drugs have been used by this route in diffuse, non-infiltrating papillary carcinoma of the bladder ${ }^{1} 2$ for several years, but intravesical thiotepa treatment has occasionally been complicated by pancytopenia and generalized sepsis. ${ }^{3}$

The absence of leukopenia should be noted. This suggests that there was negligible transvesical systemic absorption or hepatic "activation" of the drug.-I am, etc.,

Florence Nightingale Hospital,

F. R. Glover Bury, Lancs

1 Jones, H. C., Proceedings of the Royal Society Abbassian, A., and Wallace, D. M., fournal of Urology, 1966, 96, 461. Bruce, D. W., and Edgcomb, J. H., fournal of
Urology, 1967, 97, 482.

\section{Reflux and Hernia}

SIR,-With regard to your leading article on hiatus hernia and oesophageal reflux (24 July, p. 205), may I submit that the understanding of this subject lies in a deeper, more natural, approach than the ones being pursued at the present time, and that this natural approach revolves around the question of eating with hunger or without hunger. Physiologists well recognize that in the presence of real hunger there occur much stronger contractions along the walls of the stomach-the so-called hunger waves-and even 40 years ago Ivy and Farley, ${ }^{1}$ confirming the work of still earlier investigators, showed how closely the emptying-time of the stomach is determined by the hunger with which a meal is eaten. It is not surprising that S. Cohen and L. D. Harris ${ }^{2}$ have found that the oesophageal sphincter contracts more strongly as intragastric pressure risesthat it responds to the challenge. For contraction-waves along the stomach would be pointless without this synergic behaviour in the sphincter. But the opposite also holds true; in the absence of hunger the waves will be minimal and the sphincter will tend to relax, so that seepage back (oesophageal reflux) will be only too likely to occur.

After many years' practice in naval hospitals-and oesophageal reflux ("heartburn") is an exceedingly common complaint in the Service-I found that without any doubt the alleviation of this complaint lay in teaching the patient not to eat in the absence of hunger. And how much of such eating takes place in Westernized countries to-day! Either because meals are eaten automatically during conversation, or have to fit in with externa circumstances, or because so many of the tinned, processed, and deep-frozen foods that abound at the present time are sadly lacking in flavour. Given that a man is really hungry, and that some attractive food is available not greatly removed from its natural state, an attack of heartburn becomes, in my opinion, impossible. Thus, a skilfully-cooked pork chop, reckoned even then as food some what hard to digest, will, if eaten with real hunger for it, become like a ship sunk without trace; whereas a pint of milk, reckoned an easy food to digest, will, if taken without hunger, "lie like a ball on the stomach" for hours afterwards.

In the view just given the question of hiatus hernia thus becomes secondary to chronic reflux. It is a result, not a cause. All the foregoing is set out in detail in a joint work. ${ }^{3}-\mathrm{I}$ am, etc.,

T. L. Cleave

Fareham, Hants

Ivy, A. C., and Farley, G. B., American fournal Cohen, S., and Harris, L. D., New England fournal of Medicine, 1971, 284, 1053

Cleave, T L., Campbell, G. D., and Painter, N. S., Diabetes, Coronary Thrombosis and the Saccharine Diseases. 2nd edn., Bristol, John Wright, 1969.

\section{Mental Deficiency Nursing}

SIR,-As a parent of an adolescent boy I heartily endorse the letter (4 September, p. 582) stressing the importance of mental deficiency nursing. Because governments have neglected to expand subnormal hospitals and to encourage staff, we parents of subnormal children have been indoctrinated with the idea that they are better cared for at home.

We were pleased to look after our dull child as he developed into a well-adjusted teenager and it helped the rest of the family to become self-sufficient and sympathetic. But now he is much happier in his short terms in hospital than with us because we cannot keep up with his energy and he gets bored. He bites his wrists at home but not in hospital, which is practical proof of this.

We don't feel that hostels would offer the supervision and discipline that the hospital does and which he needs. Also we are not keen on these innocent youngsters wandering about, easy prey for the lawless to lead into crime. Am I a voice crying in the wilderness? Or are there others who wish to defend our hospitals and save the staff from this endless criticism of incidents which inevitably happen again and again where there is a subnormal person? The most ridiculous thing I have ever seen on T.V. was normal occupation of patients called "exploitation." The hyperactivity of these youngsters requires long spells of useful work to keep them out of mischief, as I well know.-I am, etc.,

Newton Abbot, Devon

JeAn Patey

\section{Practicalities of Nursing}

SIR,-The leading article (4 September, p 545) which denigrates Salmon schemes makes dismal reading to one who is neither a doctor nor a nurse. The fact is that the Salmon report ${ }^{1}$ was a charter which allowed nurses to experiment and to develop in an area where they were weakest-that is, in nursing administration. As the leading article says "The message that sound administration is as essential to nursing as to any other service does need getting across." The Salmon report emphasized that clinical and managerial practice could be welded so as to provide a progressive career structure. Doctors should remember that more than ever these days nursing has to compete with other attractive careers, but that in spite of this, as the leader grudgingly points out, the hospital nursing service has continued to expand. The cry seems to be that ward sisters are being "lost" to administration. The first chief nursing officer appointments were made in November 1967; at 30 September 1967 there were 30,987 (whole-time equivalent) ward sisters in post, at 30 September 1968 the figure was 31,751, and by 30 September 1970 the figure was 34,025 .

In the sphere of total management and patient care I would hope to see greater medical participation rather than indulgence in the ill-judged and hasty criticisms set out in this leader. The report Organization of Medical Work in Hospitals ${ }^{2}$ recommended (paragraph 31 ) that clinicians should play a "continuous and leading part in the management arrangements for the complex of hospital and associated institutions. . ." The new chief nursing officer whose job it is to determine nursing standards of patient care would welcome that kind of support and participation from clinicians-for instance, in obtaining a fair share of resources for nursing services, and for clinical and managerial training for nurses.

May I suggest that the medical profession which prides itself on scientific analysis, and particularly those doctors without experience of a Salmon scheme which is fully operative, reserve their comments. Though some twothirds of the top group nursing posts have now been filled few groups have appointed all other grades. Experience of those with fully operative schemes is that after a transitional period the number of posts above ward sister level need be no more than before the scheme was introduced. There has been little time yet to test the value of nursing officer posts. Doctors might actively devote themselves to extending the skill of their clinical nursing colleagues so that some of them became consultants in nursing at nursing officer level. Such a nursing officer could be the right-hand man of a number of consultants working within his/her unit, and counsellor to newly appointed ward sisters and to sisters who have returned to nursing after a lapse of years. That would be a start in the direction suggested in the leader.

It will be unforgivable if we do not have a settled and acceptable nursing administration when integration of the National Health Service occurs. Far from calling a halt to the implementation of Salmon it should be pursued with vigour so that with the parallel reorganization of local authority nurses a sound and established nursing administration can move into the integrated Service in 1974.-I am, etc.,

ISABEL GRAHAM BRYCE Chairman, National Nursing Staff Committee London W.1

Ministry of Health. Report of the Committee on
Senior Nursing Staff Structure. London,
H.M.S.O., 1965. Medical Work in Hospitals.
2 Organization of Men Wondon, H.M.S.O., 1967.
London,

\section{Queen Alexandra and the Tate}

SIR,-The extension of the Tate Gallery must be fairly low on the list of priorities and interests of the majority of the profession. Support by the profession for the retention of the Millbank hospital in opposition to the realistic expansion of the Tate Gallery may lack the detached judgement that this matter requires.

Compared with New York, London is sadly deprived of the requirements of a major museum of modern art to grace a great 